\title{
Wright-Patterson Air Force Base Educational Outreach Program
}

\author{
J. Tiley and K. Stulz
}

Air Force Research Laboratory, Wright Patterson Air Force Base, OH 45433

The Wright Patterson Air Force Base Educational Outreach Program (EO) was established through an Air Force Research Laboratory (AFRL) and Life Cycle Mangement Center (LCMC) partnership in 1999. Its main goals have been to create and sustain K-12 student interest in science, math, aviation and aerospace, and to help develop scientists and engineers to meet future AF and Department of Defense needs. AFRL provides major funding (approximately $\$ 750 \mathrm{~K}$ per year) for direct support while LCMC provides funding for the program STEM Coordinator and Deputy Coordinator. Additional operational funding and in-kind support is provided by the $88^{\text {th }}$ Air Base Wing and other Air Force base organizations. Additional program support is provided through the Ohio Educational Outreach Foundation, a not-for-profit, taxexempt 501(c) (3) organization, established in 2004.

WPAFB EO Programs are all coordinated by the EO office and supported by WPAFB Volunteers. The program has had incredible impact on local students, involving over 329,000 students since January 1999. Program information is shared with over 200 schools in 92 Ohio school districts. In fiscal year 2012, the program generated over 3000 in-kind volunteer support hours per month. The Scanning Electron Microscope Programs (SEMEDS) are a critical program within the EO efforts. Now in its $25^{\text {th }}$ year, SEMEDS brings students to AFRL labs to experience scanning electron microscope (SEM) technology first-hand. Students learn of educational backgrounds of lab personnel through direct interaction with laboratory scientists as well as specific functions of different microscope technology. With over 11 electron optic systems available, AFRL volunteers assist students in the analysis of various specimens and objects, each picked to incite discussion and student involvement

Additional EO activities include the "Wizards of Wright!", "Robotics", and the "Department of Defense (DoD) STARBASE" projects. In the Wizards of Wright!, volunteers provide free, curriculum based hands-on science and math demonstrations at local schools. Subjects include: Electricity and Magnetism, Weather, Lasers and Optics, Rocketry, Scientific Method, Math Madness, Aeronautics, Chemistry, Bubbleology and more. To date, over 3,900 demonstrations have been provided involving over 98,000 students. The "Robotics" project began with a grant from the American Society of Mechanical Engineers to conduct introductory workshops for teachers on robotics using LEGO Mindstorm Robotics Kits in 2001. The project gained attention of US FIRST (For Inspiration and Recognition of Science and Technology) who designated EO the lead organization for FIRST LEGO League (FLL), a program for 814 year-olds, in the State of Ohio. The program grew from 20 teams and over 300 students/mentors in 2001 to over 425 teams and over 6,000 students across Ohio and Northern Kentucky in 2012-13. WPAFB continues as the lead coordinating activity in Ohio, and, in partnership with Wright State University, runs the State of Ohio Championship Tournament every February at the Ervin J. Nutter Center. The project has impacted over 37,000 students. In Dec 2003, WPAFB EO received approval to host a DoD STARBASE Program. This national program is targeted toward at-risk $5^{\text {th }}$ grade students and is funded by DoD at $\$ 575 \mathrm{~K}$ per year. STARBASE Wright-Patt is one of 75 such programs across the United States and Puerto Rico and only the second to be hosted by an Active Duty Air Force Installation. STARBASE focuses on science, technology, engineering, and math (STEM), concepts, as well exposing students to positive role models as are typically found at military installations. STARBASE Wright-Patt opened for students in Oct 2004. The facility expanded in 2006, hosting more than 60 class sessions per year. Over 
15,000 students from eight area school districts have been involved with the project. STARBASE WrightPatt is in the process of expanding to host more than 100 classes in 2013.

The EO office also offers a variety of additional educational programs based on educator and student needs. These include providing classroom speakers, summer teacher immersion programs and workshops, job shadow days and support for local school science fairs and other special Science, Technology, Engineering and Math (STEM) community events. These efforts have created collaborative research ideas and led to successful development of engineering projects. WPAFB EO educational partnerships include local school districts, Wright STEPP, school improvement task forces, Junior Achievement, the American Institute of Aeronautics and Astronautics, American Society of Mechanical Engineers, Miami Valley TECH PREP Consortium, Dayton Regional Aviation Educator's Council, Dayton Aviation Heritage National Historic Park, AVETEC, Armed Forces Communications and Electronics Association, Air Force Association, Wright State University, Dayton Regional STEM Center, and many others. Through involvement in these programs, AFRL faculty often serve in mentoring capacities, helping develop students for placement in the workforce and/or in graduate programs. Additional information on these projects is available at the WPAFB Educational Outreach Website [1]. Specific information on AFRL research activities is also available, including information on the advanced electron optic and microscopy systems [2]. This presentation will describe the outreach programs and their impact on local school students and faculty, including lessons learned and recommendations for improving results.

\section{References:}

[1] http://edoutreach.wpafb.af.mil, Wright Patterson Air Force base Educational Outreach Website (2013) [2] http://www.wpafb.af.mil/AFRL, Air Force Research Laboratory, Wright Patterson Air Force Base (2013) 